NASA Technical Memorandum 107252

\title{
Early Results From Solar Dynamic Space Power System Testing
}

Richard K. Shaltens and Lee S. Mason

Lewis Research Center

Cleveland, Ohio

July 1996

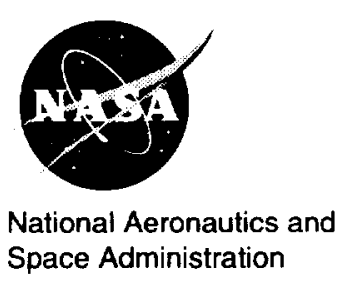




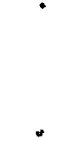




\title{
Early Results from Solar Dynamic Space Power System Testing
}

\author{
Richard K. Shaltens* and Lee S. Mason ${ }^{\dagger}$ \\ National Aeronautics and Space Administration \\ Lewis Research Center \\ Cleveland, $\mathrm{OH} 44135$
}

\section{Abstract}

A government/industry team designed, built and tested a $2-\mathrm{kW}_{\mathrm{e}}$ solar dynamic space power system in a large thermal/ vacuum facility with a simulated Sun at the NASA Lewis Research Center. The Lewis facility provides an accurate simulation of temperatures, high vacuum and solar flux as encountered in low-Earth orbit. The solar dynamic system includes a Brayton power conversion unit integrated with a solar receiver which is designed to store energy for continuous power operation during the eclipse phase of the orbit. This paper reviews the goals and status of the Solar Dynamic Ground Test Demonstration project and describes the initial testing, including both operational and performance data. System testing to date has accumulated over $365 \mathrm{hrs}$ of power operation (ranging from $400 \mathrm{~W}$ to $2.0-\mathrm{kW}_{\mathrm{e}}$ ), including 187 simulated orbits, 16 ambient starts and 2 hot restarts. Data are shown for an orbital startup, transient and steady-state orbital operation and shutdown. System testing with varying insolation levels and operating speeds is discussed. The solar dynamic ground test demonstration is providing the experience and confidence toward a successful flight demonstration of the solar dynamic technologies on the Space Station Mir in 1997.

\section{Introduction}

The NASA Office of Space Access and Technology initiated the 2-kW $\mathrm{e}$ Solar Dynamic (SD) Ground Test Demonstration (GTD) Project (refs. 1 and 2). The primary goal of this project was to conduct testing of flight prototypical components as part of a complete SD system. Demonstrations of both system power delivered and total system efficiency in low-Earth orbit (LEO) were key test objectives. The SD space power system shown in figure 1 includes the solar concentrator and solar receiver with thermal energy storage integrated with the power conversion unit, installed in a facility simulating an environment representative of LEO.

\footnotetext{
*Manager, Solar Dynamic Ground Test Demonstration Project.

†Test Director, Solar Dynamic Ground Test Demonstration Project.
}

Programs during the past 30 years have developed SD component technologies which are now available for near-Earth orbit applications. However, several technical challenges identified during the Space Station Freedom Program are currently being investigated during the GTD testing (ref. 3). These key issues are:

Flux tailoring.-integration of the concentrator and receiver such that adequate solar flux is transferred into the cycle without excessive flux deposition on any one area of the receiver, Control methodology-investigate methods of varying turboalternator compressor (TAC) speed and system thermal management in order to maintain optimum system operation (energy management) due to large time period changes in insolation, and

Transient-mode performance.- evaluation of start-up and shutdown transients, and multiple orbit operations.

The SD GTD project has demonstrated a complete SD system in a thermal/vacuum environment, i.e., the large space environmental facility, known as Tank 6, at NASA Lewis Research Center (LeRC). The Tank 6 facility includes a solar simulator to supply the equivalent of "one" Sun, a liquidnitrogen-cooled wall operating at $78 \mathrm{~K}\left(140.4{ }^{\circ} \mathrm{R}\right)$ which provides a heat sink to simulate the deep space environment (about $200 \mathrm{~K}\left(360^{\circ} \mathrm{R}\right)$ ), and an electric load simulator capable of dissipating up to $4 \mathrm{~kW}$ of electrical power. Testing in December 1994 has resulted in the world's first operation of a complete SD system in a relevant environment. SD system testing has demonstrated orbital startup, transient and steadystate orbital operation and shutdown. Flight typical components were used in the SD system wherever possible to demonstrate the availability of SD technologies. Only the power conditioning, control system and parasitic load radiator were not flight hardware designs. An overview of the GTD activities is provided by Shaltens $\&$ Boyle (refs. 4 to 6 ).

\section{Solar Simulator}

The LeRC solar simulator design consists of nine $30-\mathrm{kW}$ xenon arc lamps and provides a nominal flux of $1.37 \mathrm{~kW} / \mathrm{m}^{2}$ with a subtense angle of about 1.0 degree for testing solar 


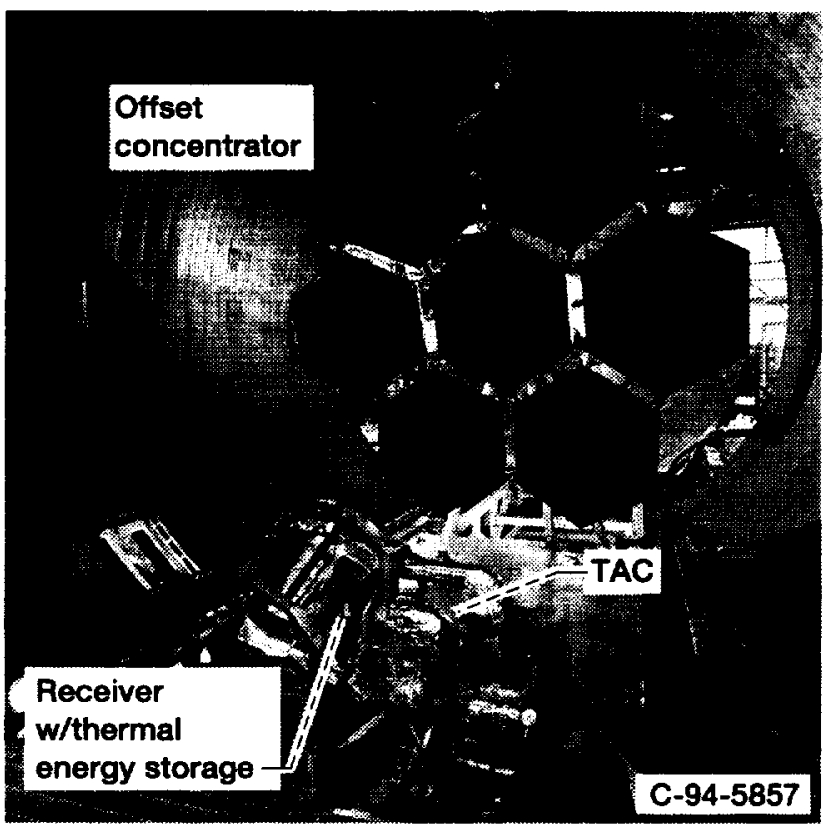

Figure 1.-Photograph of the solar dynamic system.

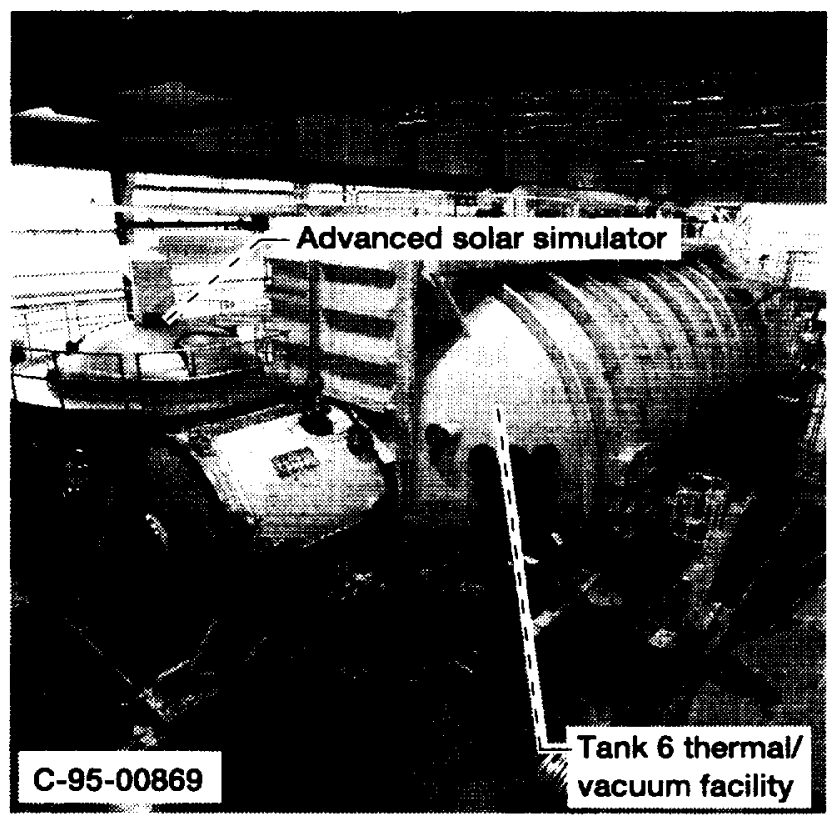

Figure 2.-Photograph of the solar simulator and tank 6.

dynamic systems. A photograph of the advanced solar simulator (in the upper left) next to the vacuum tank is shown in figure 2. This solar simulator provides an apparent "Sun" just outside the vacuum tank that shines through a quartz window into the tank to provide the desired flux (up to $1.66 \mathrm{~kW} / \mathrm{m}^{2}$ ) at the target area. The target area (i.e., concentrator interface) is $4.79 \mathrm{~m}$ in diameter and $17.2 \mathrm{~m}$ from the apparent "Sun." A water-cooled shutter is opened and closed to simulate various orbits. The advanced solar simulator system design results in a 50 percent improvement in the solar simulator system efficiency when compared to conventional designs. An advanced optics system design (new collector and lens), results in the use of only nine $30 \mathrm{~kW}$ arc lamps rather than nineteen arc lamps with a conventional optics system (ref. 7). This significantly reduces its size and initial cost as well as future operating and maintenance costs. Fabrication, assembly, installation and checkout of the solar simulator integrated with Tank 6 were completed in September 1994. A detailed description of the solar simulator design and results from early testing of a subscale optics system are discussed by Jefferies (ref. 7), while the initial operation is discussed by Jaworske (ref. 8).

\section{Solar Dynamic System}

The SD system includes the following major subsystems: (1) a solar concentrator, (2) a solar receiver with thermal energy storage, (3) a power-conversion system, (4) a waste heat rejection system, and (5) a power conditioning and control system. The SD system was designed to produce about $2-\mathrm{kW}_{\mathrm{e}}$ (at $120 \mathrm{~V}_{\mathrm{dc}}$ ) utilizing thermal energy storage with an overall system efficiency greater than 15 percent. It should be noted that the system performance and life were not optimized due to the constraints of utilizing existing hardware designed for other applications.

A block diagram of the SD system is shown in figure 3 . Energy for operating the SD system is obtained by intercepting solar radiation by use of a parabolic solar concentrator. The concentrator focuses the solar radiation into the cavity of the heat receiver. The heat receiver, which incorporates thermal energy storage, serves a dual purpose. During the on-Sun phase of the orbit, the receiver transfers the energy to the cycle working fluid and to the phase change energy storage material. During the eclipse portion of the orbit, the receiver gives up energy from the phase change material to the cycle working fluid. The hot cycle working fluid exiting the receiver is then

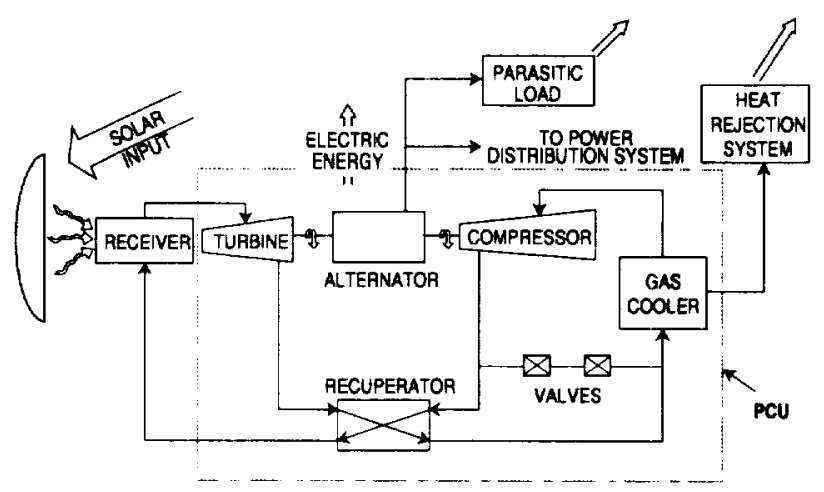

Figure 3.-Block diagram of the solar dynamic system. 
expanded through a turbine thereby producing the work necessary to turn the compressor and alternator. The working fluid passes through the recuperator (counter flow heat exchanger) which serves to pre-heat the fluid entering the receiver, thus increasing cycle efficiency. From the recuperator, the working fluid is then cooled to the compressor inlet temperature by removing the remaining waste heat energy via a gas-to-liquid heat exchanger (gas cooler). The waste heat from the cooler is dissipated by the heat rejection system. The fluid entering the compressor is compressed and used to cool the alternator before it is pre-heated at the recuperator and passed to the heat receiver.

Design life of the GTD system is for over $1000 \mathrm{hr}$ of operation with up to 100 starts from a cold condition. The nominal design case for the GTD was the maximum insolation orbit with $66 \mathrm{~min}$ of Sun and $27 \mathrm{~min}$ of shade.

\section{System Integration}

Major components of the GTD system were derived from existing designs. The TAC and recuperator came from the Brayton Isotope Power System (ref. 9) and the off-axis concentrator, solar receiver, and radiator were based on designs scaled from Space Station Freedom (ref. 2). Components were integrated based on the requirement that their interfaces be as simple as possible and that their function be readily assignable to one or another of the performing organizations. Flight packaging was not pursued because of the desire for modularity of components and simplification of their structural interfaces. The modular design of the SD system also offers the potential to evaluate advanced subsystems and components in the Tank 6 environment at a later date. Figure 4 illustrates the modular layout of the SD components as it is configured in Tank 6.

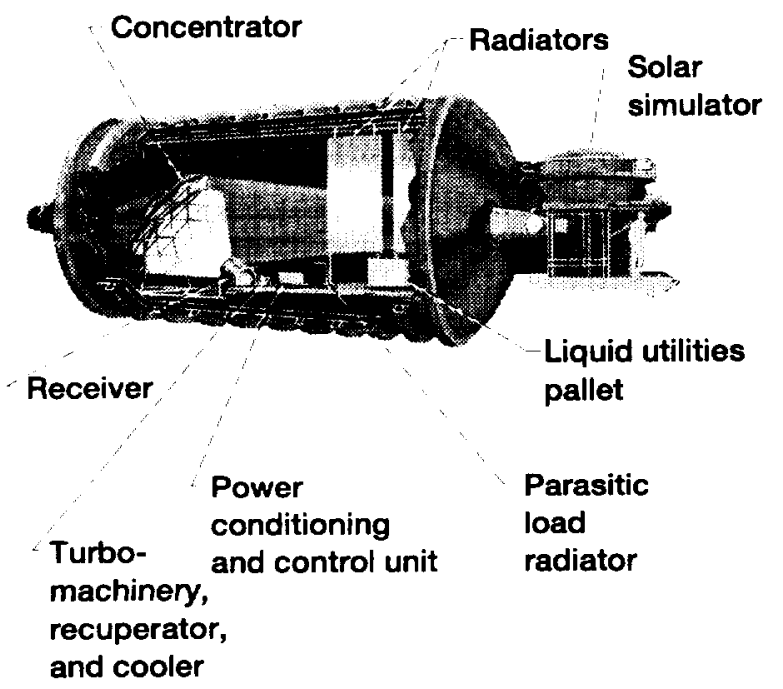

Figure 4.-Solar dynamic system layout in tank 6.

\section{Concentrator Subsystem}

As shown in figure 1, the completed offset concentrator structure consists of 7 hexagonal panels with 6 reflective facets (mirrors) per panel (ref. 10). The concentrator is $4.75 \mathrm{~m}$ wide by $4.55 \mathrm{~m}$ tall and supported on a leaning tripod support structure which attaches to a removable test stand. Facet reflectivity exceeds 85 percent and the mass is about $2.5 \mathrm{~kg} / \mathrm{m}^{2}$. After assembly, the concentrator was proof-checked on the test stand followed by facet installation and alignment. A detailed description of the offset concentrator design is provided by Bahnman (ref. 11).

\section{Receiver and Power Conversion Unit (PCU) Subsystems}

Integration of the completed solar receiver with the power conversion unit (PCU) is shown in figure 5. The receiver is used to transfer the solar thermal energy to the cycle working fluid and to store solar energy for system operation during eclipse. The receiver design is essentially a scale model from the Space Station Freedom and uses the same thermal energy storage canister (full size) as was designed, built and tested during the Space Station Freedom Program. Manufacturing, development and testing of the canisters have been completed and are discussed by Strump (ref. 12). The storage canister consists of the Haynes 188 shell, or hollow doughnut, filled with LiF-CaF 2 eutectic phase change material. The phase change material has a melting point of $1041 \mathrm{~K}\left(1873^{\circ} \mathrm{R}\right)$. Key additions to the canister tube design which provide enhanced performance are heat transfer fins added to the internal flow path and a alumina

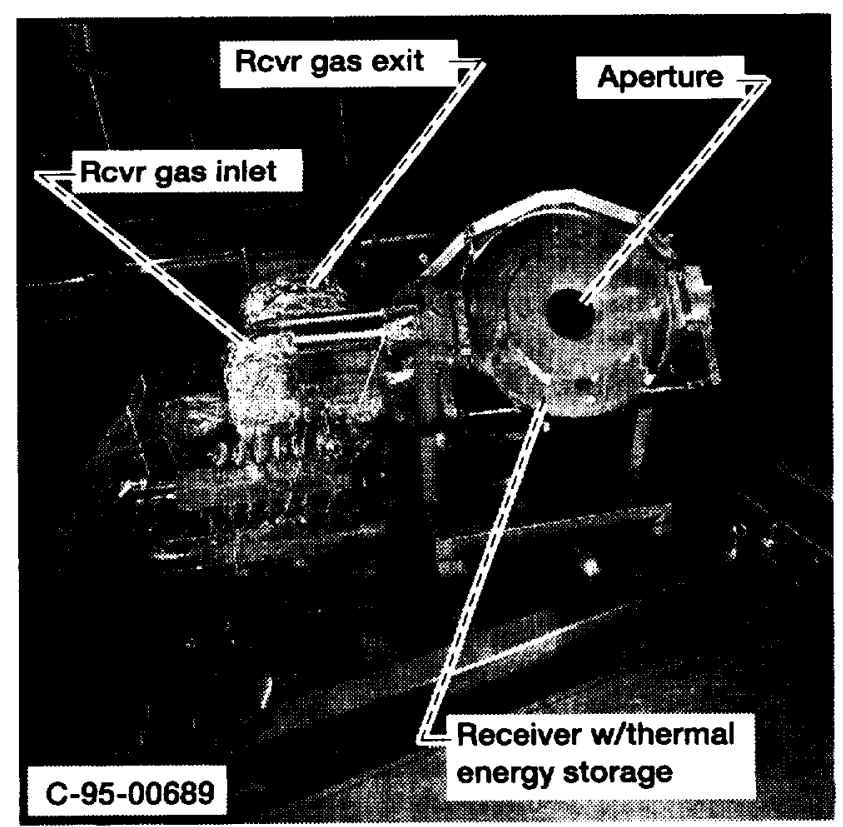

Figure 5.-Completed receiver integrated with the power conversion unit. 
based canister coating (ref. 13) for improved thermal emissivity. A complete description of the receiver design is provided by Strumph (refs. 14 and 15).

The Power Conversion Unit (PCU) subsystem is a closed Brayton cycle which includes the turboalternator/compressor (TAC), gas coolers, recuperator, ducting and support structure. The TAC, known as the mini BRU (Brayton rotating unit), consists of a single stage radial flow compressor, turbine and a brushless four pole Rice Alternator mounted on a single shaft. Foil gas bearings are used to provide long life operation by eliminating metal-to-metal contact of the shaft and bearings during operation. The altemator, bearings and shaft are cooled by the compressor discharge flow. While operating at $54000 \mathrm{rpm}$, the TAC can produce electric power up to a maximum of $2.2 \mathrm{~kW}$ (at $120 \mathrm{~V}_{\mathrm{dc}}$ ). The PCU subsystem unit uses a helium-xenon gas mixture with a molecular weight of 83.8 as the working fluid. The gas mixture was optimized for heat transfer and aerodynamic performance for the mini BRU (ref. 9). The compressed working fluid is preheated in a recuperator by turbine exhaust gases to increase efficiency of the cycle. A detailed discussion of the TAC design is provided by Amundsen (ref. 9). Acceptance testing of the PCU (known as the "hot loop" test) was completed with demonstration of $2 \mathrm{~kW}$ of electrical power. Testing was performed at local atmospheric conditions with an electrical heater. Prior to integration of the receiver and PCU, each assembly was covered with multilayer foil insulation by wrapping multiple layers of nickel and aluminum foils around the critical hot parts.

\section{Waste Heat Rejection (WHR) Subsystem}

Shown in figure 6 is the completed WHR system, which consists of two (2) identical radiator panels plumbed in series and a Liquid Utilities Pallet in a closed pumped liquid loop design. The Liquid Utilities Pallet (LUP) contains the pump(s), accumulator, sensors and an auxiliary heater for the $n$-heptane coolant fluid (ref. 16). Each bonded aluminum honeycomb radiator panel is about $1.77 \mathrm{~m}$ by $3.66 \mathrm{~m}$ with a radiating area of $12.96 \mathrm{~m}^{2}$. Each panel has 11 active and 11 inactive flow tubes evenly spaced to simulate thermal transient response of a fully redundant flow path design. Each panel is coated with a white epoxy paint, chemglaze $A 276^{\mathrm{TM}}$, a thermal control coating. The WHR system is integrated into the PCU loop by means of two gas-to-liquid heat exchanger, or gas coolers. A detailed description of the analysis, design, fabrication and testing of the waste heat subsystem is provided by Fleming (refs. 17 and 18).

Acceptance testing of the waste heat subsystem was completed in the LeRC thermal/vacuum facilities. Both steadystate and transient operation of the WHR system was conducted. Heat rejection during steady-state tests ranged from 2.5 to $6.3 \mathrm{~kW}_{\mathrm{t}}$. To meet the desired fluid outlet temperature at GTD nominal operating conditions at the lower, apparent sink temperature, radiator $\# 2$ was covered with about $1.2 \mathrm{~m}$ of insulation blankets. Performance of the WHR system was as expected.

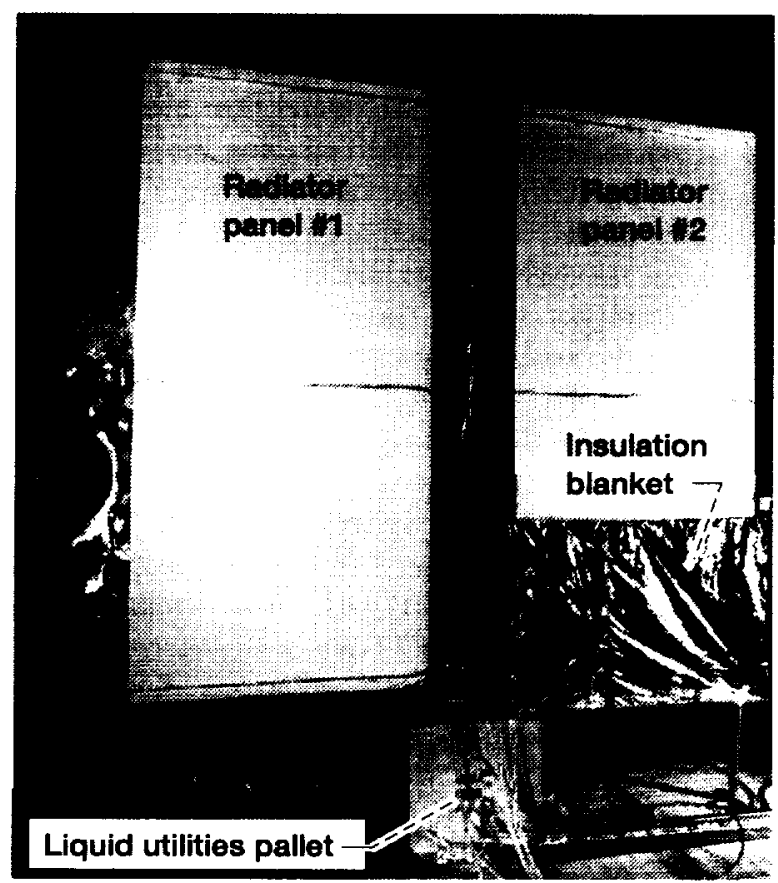

Figure 6.-Complete waste heat rejection system.

\section{Power Conditioning \& Control Subsystem}

The Power Conditioning and Control Unit (PCCU) contains the power electronics. The start inverter power supply is a commercially available, variable, controllable three-phase power supply which provides the ability to operate the TAC alternator as both an inductive and a synchronous electric motor. Starting profiles are being investigated to ascertain, by test, the optimum starting electrical characteristics. The parasitic load radiator is an integral part of the electric loop controls and functions as an electrical sink for excess power (up to 100 percent) from the TAC which is not consumed by the user load, accessory loads, and PCCU. The parasitic load radiator, which is controlled by the PCCU, consists of an array of vacuum compatible, individually controlled cal rod heaters with enhanced emissivity characteristics (ref. 13).

The Data Acquisition and Control System (DACS) is special test equipment whose primary function is to record system test data. The DACS also contains the ability to communicate setpoint conditions to the PCCU to vary speed, voltage and gain setpoints. This allows for changing the control parameters during the system test without the need to physically access the PCCU within the thermal/vacuum environment.

\section{System Operation and Testing}

Integrated system testing is being conducted over the system operating range in order to evaluate and validate previously 
developed analytical models. Testing was conducted in two phases: (1) system acceptance tests by AlliedSignal, and (2) system characterization tests by NASA (ref. 19). Operation is being conducted to characterize the SD system and evaluate various analytical models over a variety of solar insolation levels, speed conditions, orbit periods, engine inventories and radiator variations. Further, development, verification and qualification tests are ongoing in support of the joint United States/ Russian SD flight demonstration project (ref. 20).

\section{Flux Tailoring}

Verification of the optical alignment, solar simulator to concentrator to receiver optical interface surface was conducted in the thermal/vacuum environment of Tank 6 with the use of a rotating flux distribution rake. The flux-distribution rake simulated the interior cylindrical surface of the solar receiver which allows for direct measurement of the receiver flux. Comparison of the flux test data with analytical predictions showed excellent correlation. Further, the peak flux of $28.8 \mathrm{~kW} / \mathrm{m}^{2}$ compares to a worst case prediction of $42.9 \mathrm{~kW} / \mathrm{m}^{2}$. Special test equipment was provided for facet alignment and flux distribution in Tank 6 which is described by Campbell. ${ }^{21}$

\section{Control Methodology}

The SD system acceptance test included the concentrator, receiver, PCU, and WHR system in the Lewis thermal/vacuum facility with the advanced solar simulator. Acceptance testing of the SD system has successfully demonstrated startup, transient and steady-state orbital operation and shutdown. About $2.0 \mathrm{~kW}$ (peak) (at $120 \mathrm{~V}_{\mathrm{dc}}$ ) of electrical power was achieved on February 17, 1995 while operating at $52000 \mathrm{rpm}$ (design speed) with a turbine-inlet-temperature (TIT) of $1063.5 \mathrm{~K}$ $\left(1914.3^{\circ} \mathrm{R}\right)$ and a compressor inlet-temperature (CIT) of $270.2 \mathrm{~K}\left(486.4^{\circ} \mathrm{R}\right)$. Illustrated in figure 7 is an example of steady-state orbital operation (over three orbits), while operating the TAC at $52000 \mathrm{rpm}$. The average orbital user power produced

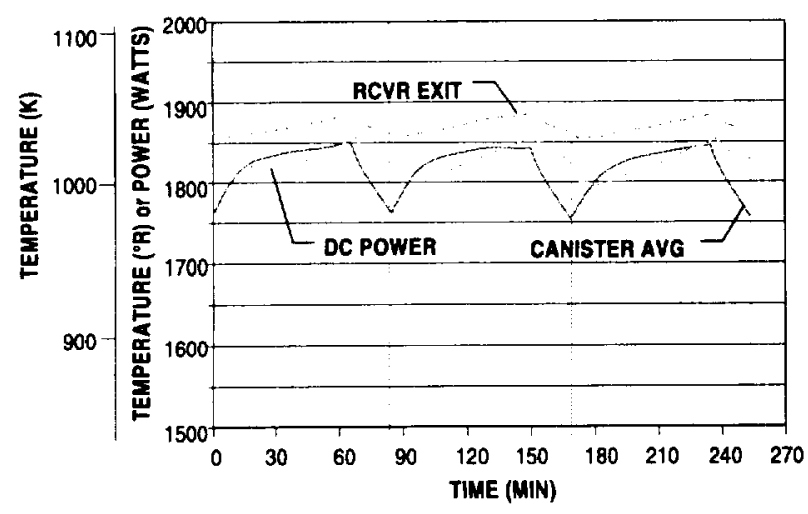

Figure 7.-Data showing steady state orbital operation. was $1.83 \mathrm{~kW}_{\mathrm{e}}$. About $107 \mathrm{~W}_{\mathrm{e}}$ of the losses are from the power electronics contained in the PCCU. Additional accessory losses include the cooling pump and the shutdown valves which are estimated at $67 \mathrm{~W}_{\mathrm{e}}$. This simulated orbit provided $66 \mathrm{~min}$ of sunlight with $18 \mathrm{~min}$ of eclipse. Also shown is the average canister temperature and the receiver gas exit temperature.

About $40 \mathrm{hr}$ of power operation with 10 orbits including 5 successful ambient starts with 1 hot restart were accumulated during acceptance testing. Ambient start temperature is defined as the receiver gas temperature at $294 \mathrm{~K}\left(530^{\circ} \mathrm{R}\right)$, while the hot start temperature is the receiver gas temperature above $778 \mathrm{~K}$ $\left(1400^{\circ} \mathrm{R}\right)$. Early evaluation of performance data showed steadystate and orbital operation of the PCU was as predicted (ref. 22). Both thrust and journal bearings temperatures and rotor stability were shown to be within acceptable limits. During the acceptance testing the following conclusions were reached: (1) system starting was slower than analytical estimates because modeling ignored certain receiver mass elements which are not critical for analysis of orbital transients; (2) the receiver pressure drop was higher than anticipated due to incorporation of heat transfer fins between the receiver tube and centerbody; (3) an overall system energy imbalance existed between receiver calorimetric calculations and solar simulator light measurements; and (4) PCCU component problems associated with vacuum and cold environmental conditions were encountered. Although differences were identified between the analytical models and actual operation of individual components, the SD system has shown to be very reliable and robust. SD system testing performed by NASA has accumulated an additional $315 \mathrm{hr}$ of power operation including 177 simulated orbits (typically $66 \mathrm{~min}$ of sunlight/27 min of shade), and 11 ambient $(294 \mathrm{~K}(530 \mathrm{R}))$ orbital starts and 1 hot $\left(778 \mathrm{~K}\left(1400^{\circ} \mathrm{R}\right)\right)$ restart.

\section{Insolation Variations}

Shown in figure 8 is a test which was conducted over a 40-hr period with the TAC operating at $48000 \mathrm{rpm}$ and illustrates an orbital startup, steady-state orbital operation and a shutdown. Data from the integrated SD system includes: the average receiver canister temperature, the receiver gas exit temperature, the compressor-inlet-temperature (CIT) and the DC power output as shown in figure 8. The solar simulator provided four different insolation levels; $1.01,1.06,1.08$ and 1.14 Suns $\left(1.37 \mathrm{~kW} / \mathrm{m}^{2}=1\right.$ Sun $)$, resulting in four steady-state orbital cases, during the 93 -min orbit. The initial orbit that produces electrical power is identified as orbit " 1 ". Balanced orbital operation was achieved on orbits 4, 8, 15, and 21 . Balanced orbital operation is defined as repeatable conditions at the same time (Sunrise or Sunset) on successive orbits, $<1.1 \mathrm{~K}\left(<2{ }^{\circ} \mathrm{R}\right)$ change in receiver gas temperatures and $<5 \mathrm{~W}$ change in power output. The first three cases (orbits 1-4, 5-8 and 9-15) are examples of operation of the heat receiver within 


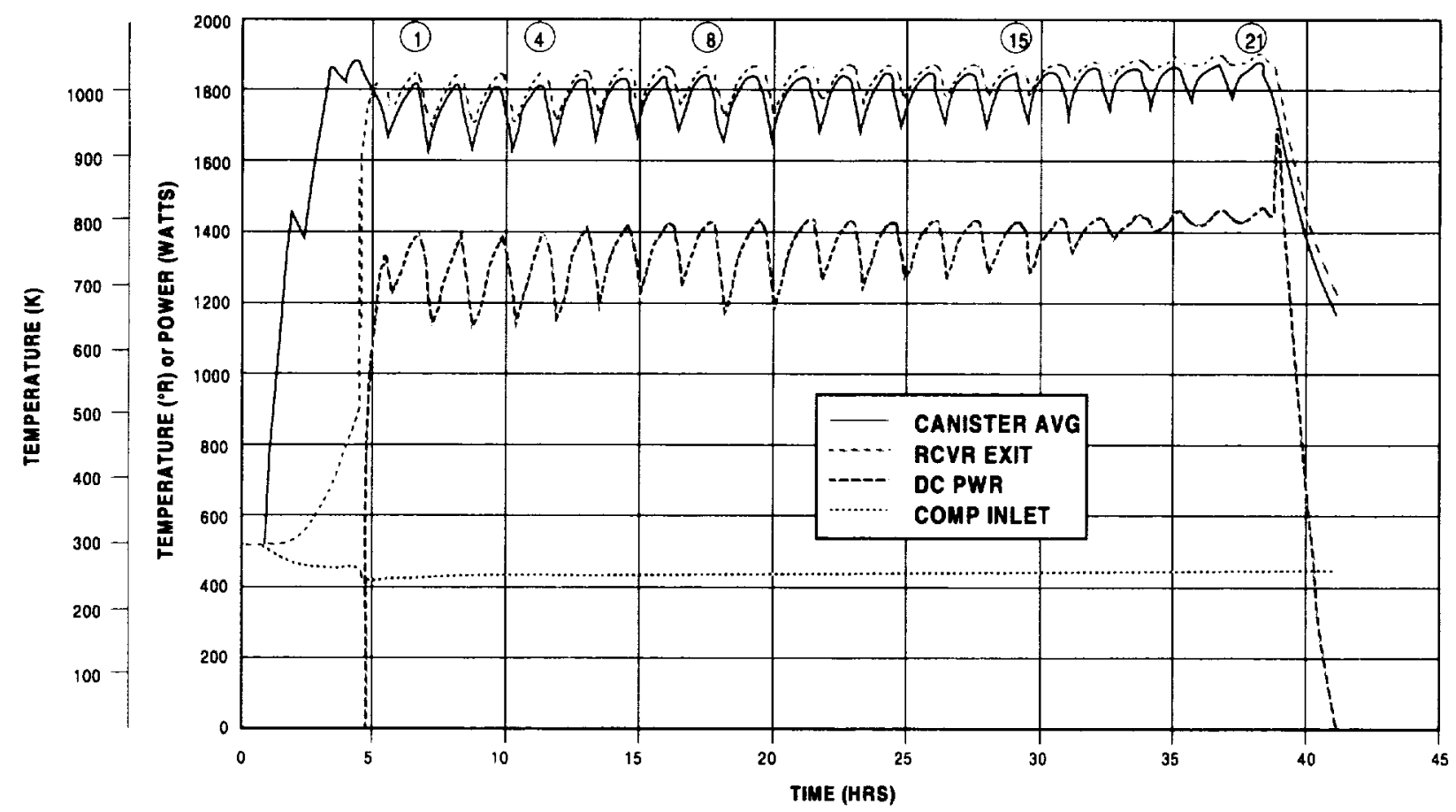

Figure 8.-Data showing startup, multiple orbits and shutdown of the SD system.

the sensible heat regime (i.e., canister phase change material not melted), which resulted in large temperature (137 K $\left(2466{ }^{\circ} \mathrm{R}\right)$ ) and power ( $\left.138 \mathrm{~W}\right)$ fluctuations. The fourth case (orbits 16-21) is in a latent heat receiver regime (i.e., phase change material melted), which resulted in a marked reduction of temperature $\left(19 \mathrm{~K}\left(34^{\circ} \mathrm{R}\right)\right)$ and power $(49 \mathrm{~W})$ fluctuations during the orbit. This is in good agreement with analytical predictions. The TAC was operating at $48000 \mathrm{rpm}$ during the test, except for the shutdown. Engine speed was increased to $52000 \mathrm{rpm}$ during the shutdown to speedup removal of the heat energy in the system. The 1.01 insolation case resulted in an overall system efficiency, Sun in to user energy, of 15 percent, with the engine efficiency of about 26 percent. Slight increases in both overall and engine efficiency were realized at the higher insolation levels.

An example of data from the orbital start-up showing a representative solar receiver heating profile is shown in figure 9 . The receiver canister temperature increases during each Sun interval of the first three orbits until it reaches $1055 \mathrm{~K}$ $\left(1900^{\circ} \mathrm{R}\right)$ during the third orbit. The turbine preheat requirement of $1055 \mathrm{~K}$ was established to overcome the potential of compressor surge effects which were observed during the "hot loop" testing of the PCU. It was discovered during "hot loop" testing that if the shutdown valves were left open and the TAC was motored, the turbine could be sufficiently preheated to eliminate surging of the compressor. Opening the shutdown valves which connect the compressor exit to the inlet was

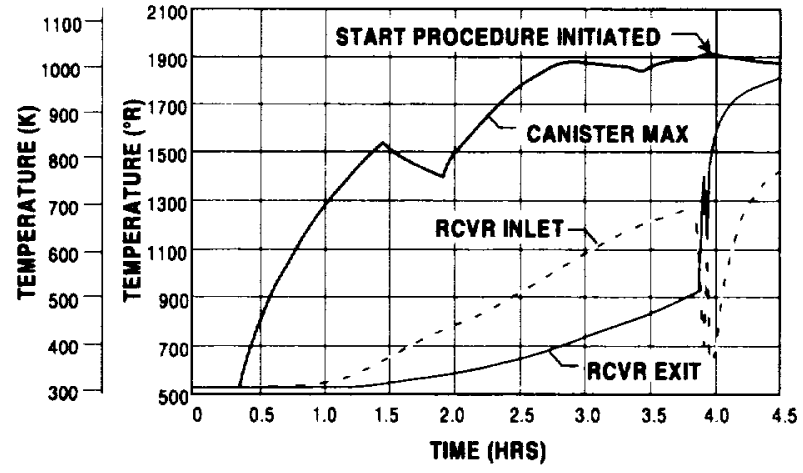

Figure 9.-Data showing ambient orbital startup.

anticipated to eliminate the compressor surge problem as these work exactly like bleed valves used on open cycle gas turbines for precisely the same purpose. Also shown are the receiver gas inlet and exit temperatures which gradually increased during the $3.5 \mathrm{hrs}$ of heating.

After the canister reached $1055 \mathrm{~K}$, the turbine preheat is conducted by motoring the TAC at $30000 \mathrm{rpm}$, with the bypass (shutdown) valves open, for about $2 \mathrm{~min}$. Note the relationship (reversal) of receiver inlet and exit temperatures during the two minute preheat, indicating proper flow direction. Finally, with the bypass valves closed, the TAC is started by motoring at $36000 \mathrm{rpm}$ until self-sustained operation is observed. TAC motoring for this start required about $4 \mathrm{~min}$. 


\section{Transient-mode Performance}

Figure 10 shows a test sequence which illustrates: an orbital startup, steady-state and transient orbital operation and a shutdown. Data from the SD system includes: average receiver canister temperature, the receiver gas exit temperature, the compressor-inlet-temperature (CIT), DC power output, and TAC speed, and are all shown in figure 10. This test was conducted over a $48 \mathrm{-hr}$ period with the TAC operating at $44000,43000,52000$ and $54000 \mathrm{rpm}$. The solar simulator provided approximately $1-S u n\left(1.37 \mathrm{~kW} / \mathrm{m}^{2}\right)$, with an orbit period of $66 \mathrm{~min}$ of sunlight and $27 \mathrm{~min}$ of shade, resulting in 27 simulated orbits producing power. Heating of the receiver cavity required three orbits. The startup criteria is defined as the maximum receiver canister temperature greater than $1055 \mathrm{~K}$ $\left(1900^{\circ} \mathrm{R}\right)$. The 1-Sun insolation level corresponds to about $10 \mathrm{~kW}$ heat to the receiver. Balanced orbital operations were achieved on orbits 5 (@44000 rpm), 14 (@43000 rpm), 21 (@52 $000 \mathrm{rpm}$ ) and 27 (@54000 rpm). Table I summarizes the receiver and engine performance for the four balanced orbits. Average power output over the orbit ranged from $1.23 \mathrm{~kW}$ to $1.34 \mathrm{~kW}$ and engine efficiency (alternator output power divided by working fluid heat input) varied from 21.5 to 26.4 percent while overall system efficiency ranged from 13.8 to 15 percent. Figure 11 shows the sensitivity of the receiver gas exit temperature and gas flow rate to TAC speed. Orbit 14 provided the only example of operation in which the receiver was in the latent heat regime.

The sequence of the speed changes was selected to effect worst case system performance transients. The change from 43000 to $52000 \mathrm{rpm}$, shown in figure 10 , provides insight into the "system" response going from a hot, latent receiver to a sensible heat receiver. This speed change is similar to what could be expected on orbit in response to excessive receiver energy input (e.g., extended Sun times due to higher orbit inclinations). Figure 12 shows the short-term receiver gas temperature and power output effects of the speed change. The dashed lines represent the response to the speed transient and the solid lines provide a reference of the same parameters at the same time in the previous orbit. The data show essentially no change in receiver gas exit temperature and a minimal (about $27.8 \mathrm{~K}\left(50^{\circ} \mathrm{R}\right)$ ) change in gas inlet temperature. As shown in figure 10 , the long term effect of the speed change was achieved 6 orbits later (orbit 21) upon achieving a balanced orbit at $52000 \mathrm{rpm}$. The transition from balanced operation (orbit 14) at $43000 \mathrm{rpm}$ to balanced conditions at $52000 \mathrm{rpm}$ resulted in a sunset temperature (i.e., maximum orbital temperature) decrease at the receiver gas exit of $61 \mathrm{~K}\left(110^{\circ} \mathrm{R}\right)$. Similar results were obtained for the 52000 to $54000 \mathrm{rpm}$ speed transient (orbit 22) with minimal short term effects and 5 transition orbits before the full impact of the speed change was observed on the receiver temperature.

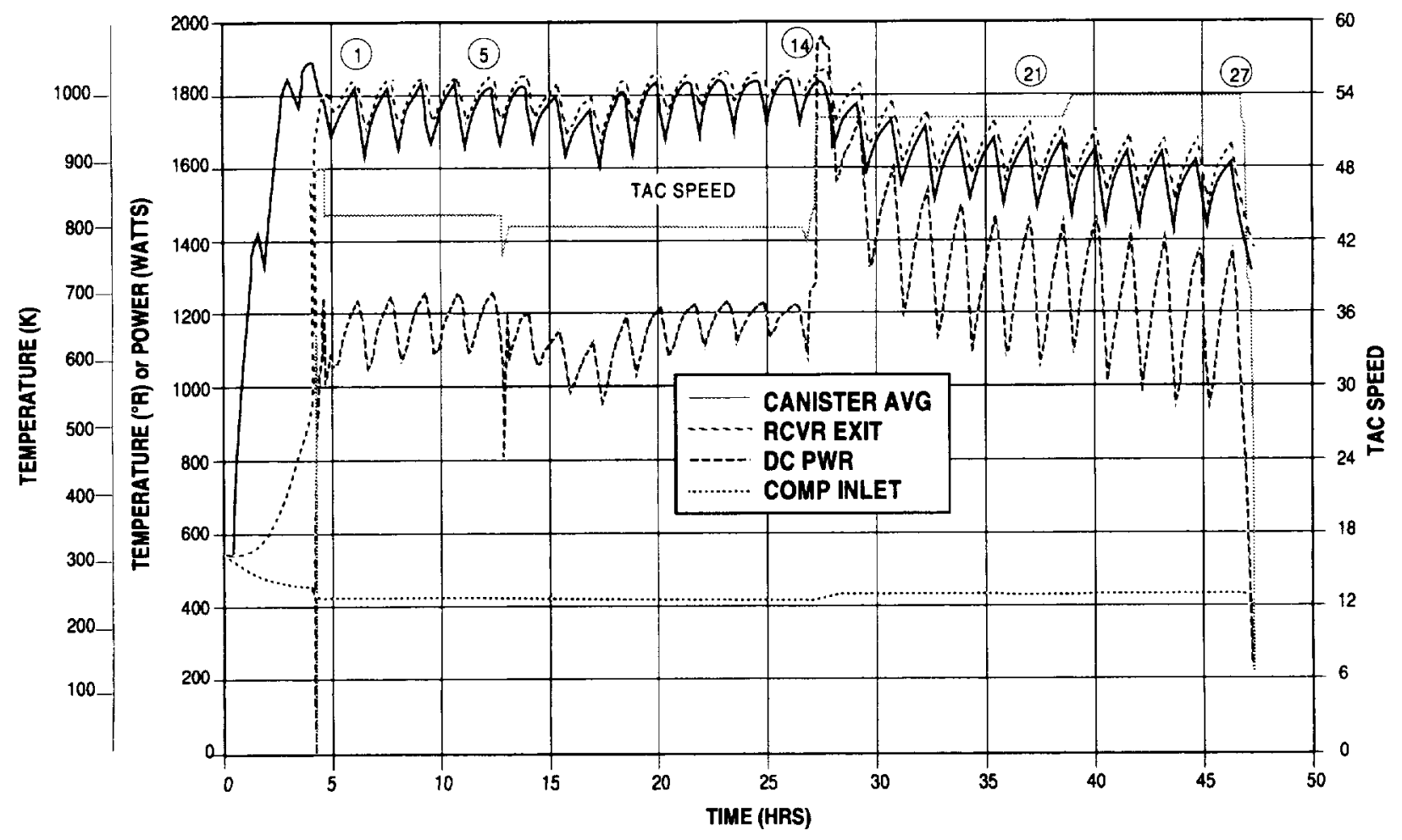

Figure 10.-Data shows TAC speed changes $(44,43,52$ and $54 \mathrm{~K} \mathrm{rpm})$ for the PCU. 
Table I.-SD system balanced orbit performance data

\begin{tabular}{|c|c|c|c|c|}
\hline \multirow[b]{2}{*}{ Parameter } & \multicolumn{4}{|c|}{ Orbit } \\
\hline & 5 & 14 & 21 & 27 \\
\hline Insolation, suns & 0.99 & 1.02 & 1.00 & 0.98 \\
\hline ac power, $\mathrm{kW}$ & 1.23 & 1.24 & 1.34 & 1.22 \\
\hline dc power, $k W$ & 1.18 & 1.19 & 1.28 & 1.17 \\
\hline Receiver exit, ${ }^{\circ} \mathrm{R}$ & 1800 & 1842 & 1654 & 1595 \\
\hline Receiver inlet, ${ }^{\circ} \mathrm{R}$ & 1542 & 1580 & 1384 & 1328 \\
\hline Compressor inlet, ${ }^{\circ} \mathrm{R}$ & 425 & 420 & 434 & 435 \\
\hline TAC speed, rpm & 44,163 & 43,143 & 52,127 & 54,016 \\
\hline $\mathrm{Q}_{\mathrm{cas}}, \mathrm{kW}$ & 4.69 & 4.67 & 5.62 & 5.70 \\
\hline Engine efficiency, percent & 26.2 & 26.4 & 23.9 & 21.5 \\
\hline Canister average, ${ }^{\circ} \mathrm{R}$ & 1758 & 1802 & 1604 & 1543 \\
\hline$Q_{\text {Loss }}, \mathrm{kW}$ & 1.73 & 1.91 & 1.20 & 1.03 \\
\hline$Q_{R C V R}, k W$ & 9.06 & 9.27 & 9.61 & 9.48 \\
\hline Orbit efficiency, percent & 14.6 & 14.4 & 15.0 & 13.8 \\
\hline
\end{tabular}

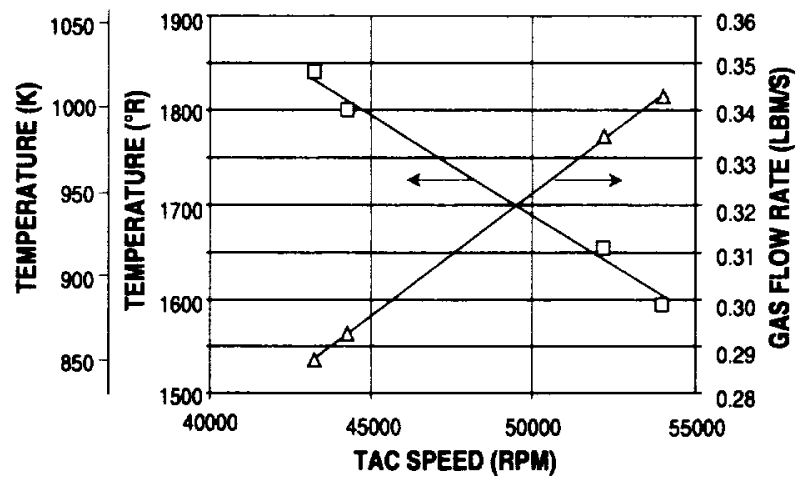

Figure 11. Sensitivity of TAC speed to temperature and flow rate.

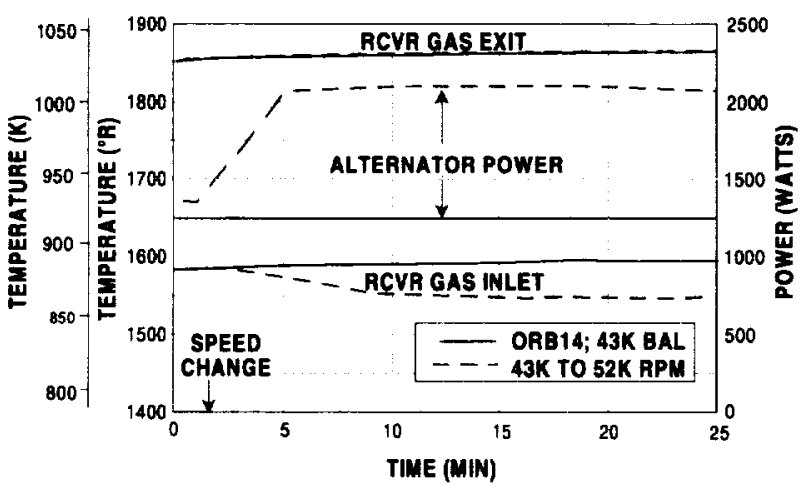

Figure 12.-Comparison of system response to TAC speed change ( 43 to $52 \mathrm{~K}$ rpm) vs. balanced orbit ( $43 \mathrm{~K} \mathrm{rpm})$.

\section{Summary}

Initial operational and performance data has demonstrated an SD power system which is of sufficient scale and fidelity to ensure confidence in the potential of SD technology for space. Integration of the solar concentrator and receiver has shown that peak fluxes within the receiver were well within worst case design predictions. System testing has successfully shown orbital startup, transient and steady-state orbital operation and shutdown in a relevant space environment with a simulated Sun. Off-design thermodynamic performance data is provided which demonstrates the flexibility of the SD system under different solar intensities and operating speeds. Over $365 \mathrm{hr}$ of power operation, ranging from $400 \mathrm{~W}$ to $2.0 \mathrm{~kW}_{\mathrm{e}}$ of power operation, including 187 simulated orbits, 16 ambient starts and 2 hot restart have been completed.

SD system efficiencies during orbital operation has ranged from 13.8 to 16.1 percent. The demonstrated end-to-end system efficiency is very good when compared to large photovoltaic/battery systems. End-to-end orbital efficiencies of large photovoltaic/battery systems are currently estimated to be about 4 percent for the International Space Station. Testing to date has resulted in an improved understanding of integrated SD system operations and performance.

\section{Acknowledgements}

\section{SD GTD Team}

The collective efforts of the SD GTD Team has resulted in the world's first full scale demonstration of a complete space-configured SD system in a large thermal/vacuum facility with a simulated Sun. The authors wish to acknowledge the contributions of the SD GTD Team Members which include: NASA LeRC, Cleveland, $\mathrm{OH}$ was responsible for overall project management and provided an advanced solar simulator with the large thermal/vacuum facility; Harris Corporation, Melbourne, FL for the offset solar concentrator; AlliedSignal Aerospace, Torrance, CA, for the solar heat receiver (with thermal energy storage) and gas cooler; AlliedSignal Aerospace, Tempe, AZ, for management of the industry team members and the power conversion system; Loral Vought Systems, Dallas, TX for the radiator panels; and Rockwell International Corporation, Rocketdyne Division, Canoga Park, CA, for system integration and test support. Aerospace Design \& Development (ADD), Niwot, CO supplied the multilayer insulation (MLI) for the heat receiver and power conversion subsystem while Solar Kinetics Incorporated (SKI), Dallas, TX supplied the reflective facets for the concentrator. 


\section{References}

1. Shaltens, R.K.and Boyle, R.V., "Initial Results From the Solar Dynamic (SD) Ground Test Demonstration (GTD) Project at NASA Lewis," TM-107004, Proceedings of the 30th Intersociety Energy Conversion Engineering Conference, The American Society of Mechanical Engineers, New York, NY, 1995, pp. 363-368.

2. Calogeras, J.E. and Dustin, M.O., "The Ground Testing of a $2 \mathrm{~kW}_{\mathrm{e}}$ Solar Dynamic Space Power System," Proceedings of the 27th Intersociety Energy Conversion Engineering Conference, Society of Automotive Engineers, Inc., Warrendale, PA, 1992, Vol. 1, pp. 455-460.

3. Jefferies, K.S., Ed., "Solar Dynamic Power System Development for Space Station Freedom." NASA RP-1310, July, 1993.

4. Shaltens, R.K., "Overview of the Solar Dynamic Ground Test Demonstration Program at the NASA Lewis Research Center," NASA TM-106876, March 1995

5. Shaltens, R.K. and Boyle, R.V., "Update of the $2 \mathrm{~kW}$ Solar Dynamic Ground Test Demonstration Project," NASA TM-106730, Proceedings of the 29th Intersociety Energy Conversion Engineering Conference, American Institute of Aeronautics and Astronautics, Washington, D.C., 1994, pp. 359-365

6. Shaltens, R.K. and Boyle, R.V., "Overview of the Solar Dynamic Ground Test Demonstration Project," NASA TM-106296, Proceedings of the 28th Intersociety Energy Conversion Engineering Conference, American Chemical Society. Washington, D.C., 1993, Vol. 2, pp. 831-836.

7. Jefferies, K.S., "Solar Simulator for Solar Dynamic Space Power System Testing," NASA TM-106393, The 1994 ASMEJISMEJISES International Solar Energy Conference, (San Francisco, CA), The American Society of Mechanical Engineers, New York, NY, March 27-30, 1994, pp. 217-222.

8. Jaworske, D.A., Jefferies, K.S., and Mason, L.S., "Alignment and Initial Operation of an Advanced Solar Simulator," AIAA Paper 96-0102, January 1996.

9. Amundsen, P.C. and Harper, W.B., "BIPS Turboaltemator-Compressor Characteristics and Application to the NASA Solar Dynamic Ground Demonstration Program," Proceedings of the 27th Intersociety Energy Conversion Engineering Conference, 1992, Society of Automotive Engineers, Inc. Warrendale, PA, Vol. 2, pp. 239-244.

10. Schertz, P., Shabbar, S. and Lammert, L., "Development of an Improved Facet for Space Applications," NASA CR-189109, October 1991.

11. Bahnman, D.W. and Jensen, P.A., "Design of a Solar Concentrator for the Solar Dynamic Ground Test Demonstration Project," The I994 ASMEJ JSMEJJSES International Solar Energy Conference, (San Francisco, CA). The American Society of Mechanical Engineers, New York, NY, March 27-30, 1994, pp. 193-203.

12. Strumph, H.J., Westelaken, B., Shah, D., Pogue, B., Chin, Jr., Alvarez, J., and Klucher, B., "Fabrication and Testing of the Solar Dynamic Ground Test Demonstration Heat Receiver," Proceedings of the 29 th Intersociety Energy Conversion Engineering Conference, American Institute of Aeronautics and Astronautics, Washington, D.C., 1994, pp. 372-377.
13. de Groh, K.K., Roig, D.M., Burke, C.A., and Shah, D.R., "Performance and Durability of High Emittance Heat Receiver Surfaces for Solar Dynamic Power Systems," The 1994 ASMEJJSMEJJSES International Solar Energy Conference, (San Francisco, CA), The American Society of Mechanical Engineers, New York, NY, March 27-30, 1994, pp. 251-264.

14. Strumph, H.J., Avanessian, V., Ghafourian, R., and Huang, F.J., "Therma and Structural Analysis of the Heat Receiver for the Solar Dynamic Ground Test Demonstrator," The 1994 ASMEJJSMEJSSES International Solar Energy Conference, (San Francisco, CA), The American Society of Mechanical Engineers, New York, NY, March 27-30, 1994. pp. 223-234.

15. Strumph, H.J., Krystkowiak, C. and Killackey, J.J., "Design of the Heat Receiver for the Solar Dynamic Ground Test Demonstrator Space Power System," Proceedings of the 28th Intersociety Energy Conversion Engineering Conference, American Chemical Society, Washington, D.C. 1993, Vol. 1, pp. 469-475.

16. Fleming, M.L., and Flores, R.R., "Radiator Selection for Space Station Solar Dynamic Power Systems," Proceedings of the 22nd Intersociety Energy Conversion Engineering Conference, American Institute of Aeronautics and Astronautics, New York, NY, 1987, pp. 208-213.

17. Fleming, M.L., Flores, R.R. and Sharpe, R.R., "Solar Dynamic Ground Test Demonstration Radiator Design and Test," Proceedings of the 29th Inter-society Energy Conversion Engineering Conference, American Institute of Aeronautics and Astronautics, Washington, D.C., 1994, pp. 378-383.

18. Fleming, M.L. and Flores, R.R., "Solar Dynamic Radiator Design Development," The 1994 ASME/JSMEJJSES International Solar Energy Conference, (San Francisco, CA), The American Society of Mechanical Engineers, New York, NY, March 27-30, 1994, pp. 245-250.

19. Mason, L.S. and Kudija, C.J., 1994, "Solar Dynamic Ground Test Demonstration System Test Plans," The 1994 ASMEJSMEJJSES International Solar Energy Conference, (San Francisco, CA), The American Society of Mechanical Engineers, New York, NY, March 27-30, 1994, pp. 175-184.

20. Huckins, E. and Ahlf, P., "Space Station Power Requirements and Issues," Proceedings of the 29th Intersociety Energy Conversion Engineering Conference, American Institute of Aeronautics and Astronautics, Wash. ington, D.C., 1994, pp. 608-612.

21. Campbell, J.S. and Jensen, P.A., "Design, Analysis and Test of a Solar Concentrator for Space Applications," The 1994 ASMEJSSMEJJSES Intermational Solar Energy Conference, (San Francisco, CA), The American Society of Mechanical Engineers, New York, NY, March 27-30, 1994, pp. 205-216.

22. Mock, T.A., "Solar Dynamic Ground Test Demonstrator (SDGTD) Systerm Orbital and Startup Control Methods," The 1994 ASMEJSMEJJSES International Solar Energy Conference, (San Francisco, CA), The American Society of Mechanical Engineers, New York, NY, March 27-30, 1994, pp. 185-191. 
Public reporting burden for this collection of information is estimated to average 1 hour per response, including the time for reviewing instructions, searching existing data sources, gathering and maintaining the data needed, and completing and reviewing the collection of information. Send comments regarding this burden estimate or any other aspect of this collection of information, including suggestions for reducing this burden, to Washington Headquarters Services, Directorate for Information Operations and Aeports, 1215 Jefferson Davis Highway, Suite 1204. Artington, VA 22202-4302, and to the Office of Management and Budget, Paperwork Reduction Project (0704-0188), Washington, DC 20503.

\begin{tabular}{|l|c|c|}
\hline 1. AGENCY USE ONLY (Leave blank) & $\begin{array}{c}\text { 2. REPORT DATE } \\
\text { July } 1996\end{array}$ & $\begin{array}{r}\text { 3. REPORT TYPE AND DATES COVERED } \\
\text { Technical Memorandum }\end{array}$ \\
\hline
\end{tabular}

4. TITLE AND SUBTITLE

Early Results From Solar Dynamic Space Power System Testing

\section{AUTHOR(S)}

Richard K. Shaltens and Lee S. Mason
5. FUNDING NUMBERS

WU-233-03-0B

7. PERFORMING ORganization NAME(S) AND ADDRESS(ES)

8. PERFORMING ORGANIZATION REPORT NUMBER

National Aeronautics and Space Administration

Lewis Research Center

Cleveland, Ohio 44135-3191

E-10176-1

9. SPONSORING/MONITORING AGENCY NAME(S) AND ADDRESS(ES)

National Aeronautics and Space Administration

Washington, D.C. 20546-0001

10. SPONSORINGMONTORING AGENCY REPORT NUMBER

NASA TM-107252

\section{SUPPLEMENTARY NOTES}

This paper is also published in The Journal of Propulsion and Power, American Institute of Aeronautics and Astronautics, Washington D.C., Vol 12, No. 5, Sept.-Oct. 1996. Responsible person, Richard K. Shaltens, organization code $5490,(216) 433-6138$.

12a. DISTRIBUTIONAVAILABILITY STATEMENT

12b. DISTRIBUTION CODE

Unclassified - Unlimited

Subject Category 20

This publication is available from the NASA Center for AeroSpace Information, (301) 621-0390.

13. ABSTRACT (Maximum 200 words)

A government/industry team designed, built and tested a $2-\mathrm{kW}_{\mathrm{e}}$ solar dynamic space power system in a large thermal/ vacuum facility with a simulated Sun at the NASA Lewis Research Center. The Lewis facility provides an accurate simulation of temperatures, high vacuum and solar flux as encountered in low-Earth orbit. The solar dynamic system includes a Brayton power conversion unit integrated with a solar receiver which is designed to store energy for continuous power operation during the eclipse phase of the orbit. This paper reviews the goals and status of the Solar Dynamic Ground Test Demonstration project and describes the initial testing, including both operational and performance data. System testing to date has accumulated over $365 \mathrm{hrs}$ of power operation (ranging from 400 watts to $2.0-\mathrm{W}_{\mathrm{e}}$ ), including 187 simulated orbits, 16 ambient starts and 2 hot restarts. Data are shown for an orbital startup, transient and steady-state orbital operation and shutdown. System testing with varying insolation levels and operating speeds is discussed. The solar dynamic ground test demonstration is providing the experience and confidence toward a successful flight demonstration of the solar dynamic technologies on the Space Station Mir in 1997.

\begin{tabular}{|c|c|c|c|}
\hline \multicolumn{3}{|c|}{$\begin{array}{l}\text { 14. SUBJECT TERMS } \\
\text { Space power; Solar dynamic; Brayton cycle; System testing }\end{array}$} & \begin{tabular}{|c|} 
15. NUMBER OF PAGES \\
11 \\
16. PRICE CODE \\
A03 \\
\end{tabular} \\
\hline
\end{tabular}

